\title{
Selected Micronutrients in Cognitive Decline Prevention and Therapy
}

\author{
Francesco Visioli ${ }^{2}$ • Emma Burgos-Ramos ${ }^{1}$
}

Received: 13 April 2015 / Accepted: 7 July 2015

(C) Springer Science+Business Media New York 2015

\begin{abstract}
Population aging is a worldwide demographic trend. Consequently, the prevalence of chronic age-related conditions such as clinically diagnosed neurological diseases, cognitive decline, and dementia will significantly increase in the near future. The important role of diets and healthy lifestyle as preventative of neurodegenerative diseases is widely accepted nowadays, and it may provide preventive strategies in very early, non-symptomatic phases of dementia well, especially because there are still no effective treatments for it. In this article, we review the known effects of selected micronutrients on the aging brain and we propose strategies for dietary improvements.
\end{abstract}

Keywords Cognitive decline · Micronutrients · Vitamins · Polyphenols · Alzheimer's

\section{Introduction}

Population aging is a worldwide demographic trend. According to the WHO, by 2040, the proportion of world population aged $\geq 65$ is believed to reach 1.3 billion (14\% of the total). Consequently, the prevalence of chronic age-related conditions such as heart problems, clinically diagnosed neurological diseases, cognitive decline, and dementia will significantly

Francesco Visioli

francesco.visioli@imdea.org

1 Laboratory of Functional Foods, IMDEA-Food, CEI UAM + CSIC, Madrid, Spain

2 Department of Molecular Medicine, University of Padova, Viale G. Colombo 3, 35121 Padova, Italy increase. Diets rich in fresh fruit, vegetables, and unsaturated fats, and low in simple sugars and salt and highly processed foods, are generally associated with a reduced risk of developing several diseases such as type 2 diabetes, cardiovascular disease, neurodegeneration, and many forms of cancer. Shared risk factors for both Alzheimer's disease (AD) and vascular diseases such as atherosclerosis, stroke, hypertension, transient ischemic attacks, cardiac disease, and apolipoprotein $\mathrm{E}_{4}\left(\mathrm{APOE} \mathrm{e}_{4}\right.$ ) genotype, obesity, and diabetes play important roles in the etiology of neurodegenerative diseases such as AD [1]. These vascular risk factors may increase the risk for AD by promoting inflammation, cerebral vascular disease, white matter lesions, hippocampal sclerosis, and mitochondrial dysfunction [1]. The important role of diets and healthy lifestyle as preventative of vascular diseases is widely accepted nowadays, and it may provide preventive strategies in very early, non-symptomatic phases of dementia as well, especially because there are still no effective treatments for AD. Recent focus is therefore on the early, asymptomatic phase of the disease especially on the (cerebro)vascular risk factors like atherosclerosis, hypertension, and obesity, etc., being modifiable via changes in lifestyle factors such as diet [2]. Recently, the Mediterranean diet has been shown in several prospective worldwide studies to be inversely associated with cardiovascular disease (CVD) and to be a strong protective factor against hypertension, obesity, and $\mathrm{AD}$ [3].

Of note, the Mediterranean diet (but also the Japanese diet [4]) is rich in micronutrients that derive from plant foods. In this respect, it has been suggested that adequate intakes of micronutrients, either consequent to a correct diet or through supplementation, might afford the elderly protection from neurodegeneration. In the cardiovascular realm, this has been referred to as the "metabolic tune-up," which should result in a marked increase in health at little cost [5]. In this article, we review the known effects of micronutrients on the aging brain 
and remark that this is a subject worth addressing in preventive medicine. Even though long-chain polyunsaturated fatty acids such as docosahexaenoic acid (DHA) are neuroprotective $[6,7]$ and have been suggested in cognitive decline prevention [6], we did not include them in this review because their suggested intake (around $500 \mathrm{mg} /$ day, see ISSFAL.org for example) does not classify them as "micro" nutrients.

\section{Alzheimer's Disease—Etiological Summary}

$\mathrm{AD}$ is an irreversible neurodegenerative disorder which stems from the interaction between multiple factors that induce progressive memory loss and cognitive decline, exacerbated by neurotransmitter deficits. Neuropathologically, AD is characterized by the presence of extracellular senile plaques containing amyloid $\beta$ peptides $(\mathrm{A} \beta)$ and intracellular neurofibrillary tangles of hyperphosphorylated tau protein [8]. The A $\beta$ peptide is formed from amyloid protein precursor (APP) by sequential enzymatic processing, in which different $\beta$-secretases and $\gamma$-secretase are involved [9]. Moreover, $A \beta$ aggregations are also tightly linked to increased oxidative stress. Oxidative stress is accompanied by mitochondrial dysfunction, pronounced inflammation, gliosis, axonal degeneration, and impairment of synaptic transmission that ultimately end in progressive neuronal loss, predominantly by apoptosis [10]. In summary, AD is a multifactorial disorder that must be addressed via a multidisciplinary approach, including proper nutrition and/or supplementation.

\section{Vitamin $\mathrm{C}$ and $\mathrm{AD}$}

Vitamin C or ascorbic acid (AA) is a powerful water-soluble antioxidant present mainly in citrus fruits, strawberries, kiwis, and some green leaf vegetables such as spinach and broccoli. It is an essential nutrient for humans given that we are incapable of producing the enzyme gulonolactone oxidase needed to synthesize AA from glucose [11]. Of note, a plethora of biochemical processes are dependent on AA, particularly in the brain that is able to store AA in great amounts. In fact, only the adrenal glands contain similar concentrations of AA. AA plays critical roles in brain development and myelin formation [12], actively participates in the synthesis of neurotransmitters such as enzyme cofactors, and it is one of the most potent antioxidant agents in the organism $[13,14]$. It should be noted that AA could represent an excellent therapeutic candidate in those neurodegenerative disorders characterized by increased oxidative stress such as AD. Some AD animal studies have been carried out in order to elucidate the mechanisms by which AA affects cognitive function and neurodegeneration. Murakami et al. [15] showed that AA attenuates A $\beta$ oligomerization in APP transgenic mice. Likewise, Harrison et al. [16] observed that short-term high-dose AA infusion $(125 \mathrm{mg} / \mathrm{kg})$ in APP/PSEN1 and wild-type mice modifies behavior, favoring spatial learning and memory. Currently, a study - carried out in an AD mice model that is unable to produce its own AA - reported that a high AA dose decreases amyloid plaques burden in cortex and hippocampal brain of these mice. Therefore, this suggests that AA could protect against $\mathrm{AD}$ [17].

Along the same lines, numerous studies have reported that AD patients show low plasma concentrations of AA [18]. Thus, the majority of clinical trials have focused on assessing whether there is a true relationship between AA deficiency and risk of developing AD. Some such trials reported negative correlations between plasma AA levels and grade of decline cognitive. However, other studies proposed that plasma AA levels are not associated with age-related cognitive impairment $[19,20]$. This discrepancy might be due to several reasons. First, plasma AA levels are dependent on daily intake, and thus, they are not truly representative of long-term consumption [21]. Second, although AA is highly concentrated in the brain, there is no association between AA brain content and plasma levels, at least according to spectroscopic assays with MRI imaging [22], a non-invasive technique. Third, there are genetic (e.g., carriers of AA expression) and non-genetic (e.g., age) factors that modulate AA absorption and assimilation in subsets of the population $[23,24]$. This could explain why during recruitment, some control participants without signs of clinical scurvy actually exhibited AA deficiency according to plasma levels.

Hence, keeping in mind the aforementioned, many publications suggested that AA supplements might decrease the risk of developing $\mathrm{AD}$ or treat it altogether [25, 26]. Yet, another subset of assays found no relationship between the intake of vitamin $\mathrm{C}$ from food or supplements and reduced likelihood to develop AD [27]. Moreover, Gu et al. [28] reported that AA intake does not affect plasma $A \beta$ levels or its related mechanism. Therefore, the available literature about the beneficial effects of diet supplementation with AA for preventing or treating $\mathrm{AD}$ is inconclusive.

Furthermore, in order to understand the precise role of AA in $\mathrm{AD}$, we would need to carry out more clinical trials, paying more attention to their design and to the recruitment of participants, e.g., based on basal AA levels. Also, future assays should consider AA levels in CSF rather than plasma as a more important marker of $\mathrm{AD}$.

\section{Vitamin B and AD}

B vitamins are a group of eight water-soluble vitamins that control a great variety of metabolic activities [29, 30]. Although their names are similar, all of them are chemically very distinct. The main dietary sources of this group of vitamins are meats, legumes, whole grains, potatoes, bananas, chili peppers, and a wide catalogue of unprocessed products. However, it is important to note that vitamin $\mathrm{B}_{12}$ (aka cobalamin) is not 
present in plant foods [29]. In this review, we focus on the role of folate and vitamin $\mathrm{B}_{12}$ in $\mathrm{AD}$. Folate is the most important methyl group donor for maintaining integrity of DNA and mitochondrial DNA, and vitamin $\mathrm{B}_{12}$ acts as cofactor in methylation and DNA synthesis. Hence, multiple acceptors are methylated through the folate- and vitamin $\mathrm{B}_{12}$-dependent methionine-homocysteine cycle [31, 32]. Deficiency of these vitamins triggers neurological disorders such as memory loss, cognitive impairment, neuropathy, myelopathy, and sensory neuropathy [33]. It is well-known that increased homocysteine levels in serum or urine are markers of folate and vitamin $\mathrm{B}_{12}$ deficiency [34]. Homocysteine is a non-protein amino acid, which derives from methionine metabolism as regulated by B vitamins. Hyperhomocysteinemia (HHcy) impairs DNA and mitochondrial DNA, causing oxidative stress and ROS production as well as increased cytosolic calcium, which induce neuronal death [35]. Recent clinical trials have reported that HHcy is involved in cognitive decline and the development of $\mathrm{AD}[36,37]$. Therefore, understanding the mechanism(s) responsible for the association between HHcy and $\mathrm{AD}$ could provide practical means to prevent or reduce the risk of AD development. Zhang et al. [38] reported augmented amyloidogenesis following direct injection of homocysteine into animal brains. A recent study has demonstrated that a folate-, vitamin $\mathrm{B}_{6^{-}}$, and $\mathrm{B}_{12}$-deficient diet induces HHcy in an AD-like mouse model and is associated with a significant acceleration of their amyloidotic phenotype [39]. Furthermore, it would be expected that an intervention with diets supplemented with folate or vitamin $\mathrm{B}_{12}$ could prevent o decrease the risk of developing AD. Accordingly, Haan et al. [40] suggested that the risk of homocysteine-induced dementia or cognitive decline might be modified by vitamin $\mathrm{B}_{12}$ supplementation. A small subset of dementias that are reversible with vitamin $B_{12}$ has been observed, and it must be underscored that this treatment is inexpensive and safe [41]. However, the majority of clinical trials seem to indicate that vitamin $\mathrm{B}_{12}$ intervention does reduce homocysteine concentrations, but that this does not lead to any benefit in terms of cognition even after long-term of supplementation [42]. In summary, accumulated evidence indicates that vitamin $\mathrm{B}_{12}$ therapy does not improve cognition in patients without preexisting deficiency. Likewise, trials of folic acid supplementation, either alone or in combination with other B vitamins, reported limited or no effect on measures of cognitive function [43]. Of note, the observed discrepancy might be due to short treatment periods, because degenerative processes often take several years before the first symptoms appear. Therefore, we would need to recruit patients with severe vita$\min \mathrm{B}_{12}$ or folate deficiency. Also, we need to consider that the doses of folate and vitamin $\mathrm{B}_{12}$ should lead to serum concentrations that greatly exceed normal values in order to observe some effect. This is of particular concern in the elderly, where cobalamin is poorly absorbed [29], leading to acquired vitamin $\mathrm{B}_{12}$ deficiency and marginal status in this population subset. Thus, appropriate strategies to monitor $B_{12}$ status and increase its absorption should be implemented.

In conclusion, further intervention studies in large samples with extended periods of follow-up are required. This will allow for further investigation of the role of vitamin $\mathrm{B}_{12}$ or folate in the onset or progression of $\mathrm{AD}$.

\section{Vitamin A and AD}

Vitamin A or retinol is a lipophilic micronutrient present in many foods from both vegetal and animal origins. In particular, adequate consumption of carrots, broccoli, pumpkin, dairy products, liver, and eggs provides the recommended daily allowance of vitamin A, i.e., $900 \mu \mathrm{g}$ (3000 IU) for men and $700 \mu \mathrm{g}(2300 \mathrm{IU})$ for women. Nevertheless, vitamin A can also be synthetized in the brain [44]. Vitamin A is also named retinol because it participates in the synthesis of retinal pigments, which are essential for eyesight. Retinoid is a generic term that includes vitamin A and its natural as well as synthetic analogs. A wide range of biological activities and processes are modulated by retinoids which bind to two classes of nuclear receptors, namely retinoic acid receptors and retinoid $x$ receptors. The brain expresses various isoforms of these receptors [45]. Accumulated evidence demonstrates that retinoids play an important role in processes strongly related to $\mathrm{AD}$ such as production of amyloid beta, inflammation, neurotransmission, and neurogenesis [46]. In addition, the synthesis of retinoid acid is inhibited by the amyloid beta peptide, thus exacerbating AD pathology [47]. Some authors have shown that vitamin A possesses antioxidant, neuronal-protective, and antioligomeric effects in in vitro and in vivo models of $\mathrm{AD}$ [48]. In the same way, disruption of the retinoid-signaling pathway in adult rats caused an accumulation of amyloid beta in the brain [49]. Moreover, vitamin A deficiency induces a downregulation of retinoid receptors, impairing short- and long-term memory and even potentiating depression in mice [50]. Likewise, preclinical studies of retinoids in transgenic mouse models of AD showed that retinoic acid decreased activation of microglia and astrocytes and improved spatial learning and memory [51]. Vitamin A-deprived mice showed a loss of hippocampal long-term potentiation, which was fully reversible by standard diet or direct administration of retinoic acid [52]. Thus far, all studies seem to support the hypothesis that vitamin $\mathrm{A}$ is an important molecule in the prevention and therapy of AD.

Lopes da Silva et al. [53] have demonstrated that these differences are due to the fact that the $\mathrm{AD}$ and control populations presented different nutritional status when they were recruited. However, when this difference is taken into consideration, $\mathrm{AD}$ patients exhibited significantly lower vitamin A status with respect to the control cohort. Theoretically, therapies with retinoids could be used to mitigate the vitamin A 
deficit and, in turn, prevent $\mathrm{AD}$. Along these lines, numerous preclinical studies carried out in mouse models of AD showed that administration of all-trans retinoic acid (ATRA) decreases amyloid accumulation and tau hyperphosphorylation and improves cognitive decline by gene expression modulation of different molecules involved in these activities [51, 54]. Similar observations have been reported with tamibarotene (AM80) and acitretin, synthetic retinoid acid analogs which upregulated ADAM10, an enzyme implicated in nonamyloidogenic processing of APP [55]. Several phase II clinical trials (NCT01120002 and NCT01078168 clinical trials.gov identifier) are ongoing, in order to test the effects of retinoids in patients with AD. However, it should be underscored that the administration of retinoids may trigger some adverse reactions in certain patients. ATRA is extremely toxic at its chemotherapeutic dose of $45 \mathrm{mg} / \mathrm{m}^{2} /$ day, even at 90 days after treatment initiation; therefore, its use is limited in older populations, who are-however-more prone to develop AD. Moreover, prolonged retinoid usage produces gastrointestinal hemorrhage and abdominal pain [55], and extreme caution must be exerted.

In conclusion, the evidence available from preclinical studies shows that retinoids possess antiapoptotic, antioxidant, pro-differentiative, antiamyloidogenic, and antiinflammatory activities. Thus, vitamin A and its analogs might be considered as potential candidates for AD therapy. Yet, more clinical trials and toxicity assays are needed to elucidate the therapeutic role of vitamin A in AD.

\section{Vitamin D and AD}

Vitamin D belongs to the group of fat-soluble vitamins and is responsible for the intestinal absorption of various ions. It is also involved in calcium homeostasis and metabolism. Vitamin $\mathrm{D}$ is chiefly synthesized in the skin, following exposure to sunlight. In fact, fish and eggs are only foods that contain a vitamin D in noteworthy concentrations. Vitamin D from cutaneous synthesis and dietary intake is activated by hydroxylation in liver and kidney, producing 1,25-dihydroxyvitamin D that is the main circulating metabolite of vitamin D [56]. This molecule executes its functions by binding to its vitamin Dspecific receptor. Many studies have reported that vitamin D presents a high affinity to this receptor in several brain regions and different cellular types; also, it has been demonstrated that the vitamin D receptor is widespread in the human brain. As an example, Eyles et al. described the existence of vitamin D receptors in the hippocampus, one of the main brain regions affected by AD [57]. Further, vitamin D signaling is involved in brain developing and function.

On the other hand, it is well known that the elderly are at a high risk of developing vitamin D deficiency due to decreased cutaneous synthesis [58] and dietary intake [59]. However, the intestinal absorption of vitamin D is not affected by age [60].
Until date, many clinical trials have found a strong association between low vitamin $\mathrm{D}$ concentrations and an increased risk of all-cause dementia and AD. All authors agree that vitamin D supplementation might have protective effects [61, 62]. Preliminary in vitro studies showed that vitamin D increases clearance and $\mathrm{A} \beta$ phagocytosis by macrophages of $\mathrm{AD}$ patients and reduces amyloid-induced cytotoxicity and apoptosis in primary cortical neurons [63]. The administration of 1,25dihydroxyvitamin $D$ decreases cerebral $A \beta$ accumulation and improves cognition in mouse models of AD [64]. Based on these findings, several clinical trials have been carried out to evaluate the effects of vitamin D supplementation on cognition in elderly patients. The results obtained thus far are controversial, as there is discrepancy about the methods used to evaluate cognition decline, the treatment period, and doses and form of vitamin $\mathrm{D}$ : The literature shows that vitamin $\mathrm{D}_{3}$ is more bioavailable than vitamin $\mathrm{D}_{2}$. Furthermore, some authors suggest treating older patients with higher dose of vitamin $\mathrm{D}$ in order to ascertain if there is any neuroprotective effect of this vitamin [65]. Hence, more clinical trials should be carried out in order to confirm whether vitamin D supplementation could be used to delay or prevent the onset of $\mathrm{AD}$ in older adults.

\section{Vitamin E and AD}

Vitamin E was first described by Evans and Bishop [66] as a family of lipid-soluble compounds that encloses four tocopherols and four tocotrienols: $\alpha$ (alpha), $\beta$ (beta), $\gamma$ (gamma), and $\delta$ (delta): All of them are referred to as vitamin E. The tocopherols are saturated forms of vitamin $\mathrm{E}$, whereas the tocotrienols are unsaturated and possess an isoprenoid side chain. $\alpha$-Tocopherol is the most abundant biologically active form in nature [67]. The majority of vegetable oils are rich in all four tocopherol forms in different proportions, and tocotrienols are found in certain cereals and seeds such as wheat germ, oats, hazelnuts, maize, sunflower seeds and palm oil, rice bran oil, and poppy seed oil [68]. Numerous studies have shown the antioxidant properties of the vitamin $\mathrm{E}$ in a large variety of pathologies such as cancer, cardiovascular, and neurodegenerative alterations [69-71]. Vitamin E is able to scavenge free radicals converting them in less reactive compounds, favoring the cells' normal function. However, recent studies have demonstrated that vitamin $\mathrm{E}$ also possesses important activities non-related to its antioxidant activity [72]. Vitamin E inhibits or activates several enzymes involved in different signaling cascades and also modulates the expression of some genes [73]. Moreover, some vitamin $E$ forms have been attributed antiinflammatory effects [74]. Therefore, its ample array of biological activities could explain, in part, the beneficial effects of vitamin $\mathrm{E}$ on various pathologies whose 
triggering agents are totally different. In this review, we focus on the effects of vitamin $\mathrm{E}$ in Alzheimer's disease. It is widely accepted that the extracellular deposits of amyloid beta peptide and neurofibrillary intracellular tangles of hyperphosphorylated tau protein are the foremost etiological agents of $\mathrm{AD}$. A recent study described how vitamin $\mathrm{E}$ prevents the activation of $\mathrm{p} 38 \mathrm{MAPK}$, whose activity is essential for phosphorylation of neuronal tau molecules [75]. In the last decade, the combination of in vitro and in vivo experiments has suggested a protective antioxidant role of vitamin $\mathrm{E}$ in the $\mathrm{AD}$ context [76]. Administration of vitamin $\mathrm{E}$ encapsulated into nanospheres decreases levels of amyloid beta-induced reactive oxygen species in the SH-SY-5Y human neuroblastoma cells [77]. Also, this vitamin protects against the oxidationmediated decrease of synaptic proteins involved in neurotransmission, hence delaying cognitive decline [78]. Additionally, in vivo studies of $\mathrm{AD}$ are suggesting that vitamin E modulates the abnormal inflammatory response associated to this disease [79]. Nevertheless, apart from antioxidant and antiinflammatory properties, other studies have attributed certain antiamyloidogenic actions to vitamin E, because it decreased $A \beta$ levels and the global volume of senile plaques in the early stages of $\mathrm{AD}$ [80]. According to Huebbe et al., $\alpha$-tocopherol is able to modulate amyloid precursor protein processing by regulating mRNA concentrations of secretase enzymes [81]. Therefore, when considering these studies, we can postulate that vitamin E might be useful in treating $\mathrm{AD}$ based on its beneficial properties here described. In consonance with this conclusion, it has been shown that long-term feeding of rats with a diet supplemented with vitamin $\mathrm{E}$ protects against agerelated cognitive decline [82]. However, this conclusion has not been undoubtedly confirmed by current clinical trials. If any, all of the clinical evidence obtained thus far concedes that there is an inverse correlation between vitamin E plasma concentrations and progression rate of AD [18]. Therefore, it is reasonable to expect that a diet enriched or supplemented with vitamin E would improve cognitive impairment or its progression to $\mathrm{AD}$. A prospective study from Morris and colleagues reported that individuals with higher vitamin $\mathrm{E}$ intake from diet and supplements showed reduced cognitive decline and risk of developing $\mathrm{AD}$ when compared to control, i.e., low vitamin $\mathrm{E}$ intake individuals [83]. In a similar study, the authors recorded a lower risk of developing $\mathrm{AD}$ in individuals consuming foods rich in vitamin E [26]. Likewise, a cohort study evaluated the relationship between $\mathrm{AD}$ and the plasma concentrations of all vitamin E forms; the authors reported an association between low plasma tocopherol and tocotrienol levels and increased probability to develop $\mathrm{AD}$ [83]. Indeed, epidemiological studies report that vitamin $\mathrm{E}$ from food sources, i.e., the more bioavailable [84] natural form is more effective at preventing age-related neurodegenerative disorders than dietary supplementation [85]. Congruently, several clinical trials have indicated that vitamin $\mathrm{E}$ supplementation has no beneficial effects against cognitive impairment or the progression to $\mathrm{AD}[86,85]$. In brief, there appears to be some discrepancy about the putative beneficial effects of vitamin $\mathrm{E}$ in patients with $\mathrm{AD}$. Some explanations have been proposed to explain, in part, these controversial results. Firstly, the criteria to recruit patients with $\mathrm{AD}$ are different among the various clinical trials. The vitamin $\mathrm{E}$ dose, period of treatment, and the tests employed to evaluate cognitive impairment are very variable between the different trials. Further, in majority of trials, vitamin $\mathrm{E}$ supplements were $\alpha$-tocopherol and the other forms have not been not employed. A recent study has demonstrated that tocotrienols are more potent radical scavengers than $\alpha$-tocopherol [68]. It has also demonstrated that $\gamma$ tocopherol has greater antiinflammatory property than $\alpha$ tocopherol [87]. Consequently, the inconclusive results obtained from clinical trials might be partly due to the fact that the investigators did not take into consideration these aspects. One final issue that deserves attention is the fact that the systemic antioxidant actions of vitamins $\mathrm{E}$ and $\mathrm{C}$ have never been clearly demonstrated in humans; therefore, we should be careful when we attribute the purported beneficial effects of these vitamins to mere antioxidant activities.

In conclusion, additional clinical trials should be carried out with other forms of vitamin $\mathrm{E}$ in order to elucidate its potential beneficial properties toward $\mathrm{AD}$ treatment and prevention.

\section{Vitamin K and AD}

Vitamin $\mathrm{K}$ belongs to the fat-soluble vitamin group. There are two biologically active forms $\left(\mathrm{K}_{1}\right.$ and $\left.\mathrm{K}_{2}\right)$ and other synthetic analogs $\left(\mathrm{K}_{3}, \mathrm{~K}_{4}\right.$, and $\left.\mathrm{K}_{5}\right)$. Vitamin $\mathrm{K}_{1}$ (phylloquinone) is the most common form of vitamin $\mathrm{K}$ and is present in several plants, especially in leaf vegetables, certain vegetable oils, and in fruits, tubers, and seeds. Vitamin $\mathrm{K}_{2}$ or menaquinone occurs in animal products such as meat, eggs, cheese, and curd [88]. With respect to its analogs, vitamin $\mathrm{K}_{3}$ or menadiones is a synthetic molecule used to treat vitamin $\mathrm{K}$ deficiency and as food supplement $[88,89]$. All these forms of vitamin $\mathrm{K}$ possess antihemorrhagic property and participate in bone metabolism [90], even though other novel pharmacological and therapeutic activities have been discovered in recent years, including antioxidant and repressor of vascular calcification and neurological disorders associated to aging. Likewise, Allison has been the first one who reported that vitamin $\mathrm{K}$ deficiency is associated with $\mathrm{AD}$ pathogenesis, 
because - in that study - plasma concentrations of vitamin $\mathrm{K}$ were lower in patients with a high genetic risk factor for developing $\mathrm{AD}$ than in healthy patients with the same age [91]. Of note, vitamin $\mathrm{K}$ deficiency promotes collagen mineralization in the intima and, thus, loss of vasomotion [92]. A recent clinical trial found that patients with early stage Alzheimer's disease consumed less vitamin $\mathrm{K}$ than did cognitively intact control subjects, which explains the vitamin $\mathrm{K}$ deficiency recorded in these patients [93]. Additionally, other studies have demonstrated that such hypovitaminosis is related to the greater prevalence of hip fractures observed in patients with AD [94]. Finally, in vitro and spectrometric assays have demonstrated that vitamin $K_{3}$ analogs inhibit $A \beta$ aggregation and protect cells against $\mathrm{A} \beta$-induced cytotoxicity [95]. Hence, accessible evidence is indicating that vitamin $\mathrm{K}$ could play a pivotal role in $\mathrm{AD}$; there is also no current evidence that long-term administration of vitamin $\mathrm{K}$ produces undesirable effects. The efficacy of exposure to sunlight and of a diet supplemented with calcium, vitamin $\mathrm{K}_{2}$, and vitamin D against hip fractures - which afflict AD patients - has been demonstrated [96], even though it is impossible to ascertain the individual contributions of these micronutrients. Further, no clinical trials assessed the potential antiamyloidogenic effects of vitamin $\mathrm{K}$ in patients with $\mathrm{AD}$, notably in their quintessential cognitive decline. In summary, vitamin $\mathrm{K}$ appears to be a promising agent in $\mathrm{AD}$ therapy, but more in vitro and in vivo studies together with appropriate clinical trials should be carried out to discern the true role of this molecule as a viable treatment of $\mathrm{AD}$.

\section{(Poly)phenols and AD}

In addition to vitamins, humans also eat fairly large amounts of (poly)phenols, which might play some healthful roles on neurodegenerative disorders [97]. Some of these compounds indeed improve certain pathologic features of $\mathrm{AD}$ in animal models, likely because of their mitochondria-augmenting activities [97]. (Poly)phenols from different fruits and beverages such as blueberries, grapes, apples, turmeric, green and black teas, wine, coffee, and cocoa possess multiple health activities, which may - theoretically_reduce the risk of AD [97]. It has been reported that phenolic compounds from bilberry and blackcurrant extracts possess antiamyloidogenic activity and alleviate behavioral abnormalities in a mouse model of $A D$ [98]. Also, antiinflammatory properties have been granted to apple and green tea beverages, because they decrease proinflammatory cytokine levels in initial phase or moderate phase AD patients [99]. Tea, whether green or black, is rich in (poly)phenols endowed with in vitro antioxidant activities, which have been suggested to explain their putative neuroprotective actions. Nonetheless, other properties have been attributed to such neuroprotective and antiamyloidogenic (poly)phenols [100, 101].

Several epidemiological reported a reduction of dementias and Alzheimer's risk associated with moderate alcohol use, as compared with abstainers, with extents of risk reduction that vary among studies and meta-analyses [102]. Mechanistically, ethanol is able to reduce synaptic damage induced by betaamyloid and synuclein [103]. Also, some in vitro studies reported that resveratrol possesses antiamyloidogenic activity, reducing the level of secreted or intracellular $A \beta$ peptides [104]. Moreover, this (poly)phenol is able to reduce - still in vitro - the oxidative stress typical of $\mathrm{AD}$, by reducing neuronal death and suppressing activation of astrocytes and microglia [105]. Despite these encouraging in vitro data, it is very unlikely that resveratrol is responsible for the preventive activities of wine, because (1) wine contains resveratrol in trace amounts [102]; (2) risk reduction is not exclusive to wine and is seen across all alcoholic beverages [102]; and (3) resveratrol is not bioavailable and its human activities are questionable to say the least $[106,107]$.

Another (poly)phenol-rich food item that is attracting attention is turmeric, whose rhizome contains the yellow pigment curcumin, which is used as food preservative and spice. Substantial in vitro evidence indicates that curcumin has antiamyloidogenic, antioxidant, and antiinflammatory properties, all of which suggest its potential to prevent AD [108]. Frautschy et al. [109] suggested that curcumin might prevent $A \beta$-mediated synaptic deficits, because curcumin-fed/A $\beta$ injected rats exhibited better memory function compared to A $\beta$-injected rats. Again, curcumin is poorly bioavailable, and its human activities remain to be fully proven.

Along the same lines of research, coffee, a complex mixture of (poly)phenolic components, diterpenes and caffeine, might possess beneficial effects on cognitive and neurological health. Some preclinical studies have demonstrated that chlorogenic acid, the main phenol present in coffee [110], prevents $A \beta$-induced oxidative stress and exerts neuroprotective effects by inhibiting overactivated neuronal enzymes responsible for the hydrolysis of neurotransmitters [111, 112]. Likewise, clinical studies suggest that chlorogenic acid supplementation could protect against cognitive degeneration [113]; however, no formal and well-controlled studies have been performed to date to confirm or disprove this hypothesis. Also, it is currently very difficult to discriminate the effects of coffee (poly)phenols such as chlorogenic acid from those of caffeine. In synthesis, the evidence pro or against neuroprotective effects of coffee intake is still inconsistent [114].

Finally, cocoa and chocolate contain (poly)phenols in copious amounts, together with some other compounds with potential biological activity [115]. It has been shown that polyphenols from cocoa interact with signalization cascades that lead to the inhibition of neuronal death by apoptosis and promote neuronal survival and synaptic plasticity [116]. In 
addition, cocoa preserves murine cognitive abilities during aging, lowering the risk of developing $\mathrm{AD}$ [117]. It has been suggested that cocoa (poly)phenols activates the brain-derived neurotrophic factor (BDNF) survival pathway because of their antioxidant properties [116]. One aspect that needs elucidation is when consumption of cocoa and chocolate should be initiated to generate beneficial effects (if any) on age-dependent cognitive decline and neurodegenerative diseases [118].

It is noteworthy that no human intervention studies of green and black tea, wine (poly)phenols, curcumin, or cocoa in $\mathrm{AD}$ have been reported. Therefore, the extrapolation of in vitro and in vivo (animals) studies to the human situation still requires properly designed clinical trials.

\section{Conclusions}

Age-related cognitive decline is one of the major health challenges we are facing. Indeed, life expectancy is constantly increasing worldwide, which provokes major social imbalances as well as an increased burden on the national health care systems. There are currently no viable pharmacological tools to treat cogitive decline; therefore, several multidisciplinary preventive approaches to this disorder are being developed. Certainly, the implementation of correct diets and/or the use of adequate supplements appears of paramount importance in the elderly. Nevertheless, there are very few controlled and good-quality studies addressing the variegated effects of some dietary or pharmacological agents on mild cognitive decline and neurodegeneration as associated with age. In the case of micronutrients (as reviewed here), most of the available evidence comes from epidemiological and in vitro studies and clearly underscores the need to follow healthful diets and proper lifestyles, starting early in life. While attention is habitually paid to the macronutrient profile of diets and to caloric intake, emphasis should also be placed on essential fatty acids and micronutrients, namely vitamins and polyphenols, whose role appears to be crucial in $\mathrm{AD}$ prevention. Also, we might need to emphasize the potential preventive activities of some micronutrients in other forms of cognitive decline: Conceivably, milder forms might benefit the most from proper micronutrient intake.

One unresolved issue is whether lower serum concentration of several nutrients is due to disease-specific mechanism or due to the often poor nutritional intake and thus status of $\mathrm{AD} /$ dementia patients (or both). Yet, we still need properly executed clinical trials with reliable markers of cogitive decline; however, the possibility to formulate evidence-based nutraceuticals/supplements/ functional foods targeted at the elderly should find a pertinent place in the "healthy aging" decalogue.
Acknowledgments Supported by a grant from the Spanish Ministerio de Ciencia e Innovación (AGL2014-56464), European FEDER Funds, Programa de actividades en tecnologías ALIBIRD-CM S2013/ABU2728 de la Comunidad de Madrid.

\section{References}

1. Muller WE, Eckert GP, Sun GY, Wood WG (2012) Alzheimer's disease: new perspectives on therapeutic targets and pathways. Foreword. Mol Neurobiol 46(1):1-2. doi:10.1007/s12035-0128306-5

2. Barnard ND, Bush AI, Ceccarelli A, Cooper J, de Jager CA, Erickson KI, Fraser G, Kesler S, Levin SM, Lucey B, Morris MC, Squitti R (2014) Dietary and lifestyle guidelines for the prevention of Alzheimer's disease. Neurobiol Aging 35(Suppl 2): S74-S78. doi:10.1016/j.neurobiolaging.2014.03.033

3. van de Rest O, Berendsen AA, Haveman-Nies A, de Groot LC (2015) Dietary patterns, cognitive decline, and dementia: a systematic review. Adv Nutr (Bethesda, Md) 6(2):154-168. doi:10. 3945/an.114.007617

4. Hu N, Yu JT, Tan L, Wang YL, Sun L (2013) Nutrition and the risk of Alzheimer's disease. Biomed Res Int 2013:524820. doi:10. $1155 / 2013 / 524820$

5. Ames BN (2004) A role for supplements in optimizing health: the metabolic tune-up. Arch Biochem Biophys 423(1):227-234

6. Afshordel S, Hagl S, Werner D, Rohner N, Kogel D, Bazan NG, Eckert GP (2015) Omega-3 polyunsaturated fatty acids improve mitochondrial dysfunction in brain aging - impact of Bcl-2 and NPD-1 like metabolites. Prostaglandins Leukot Essent Fatty Acids 92:23-31. doi:10.1016/j.plefa.2014.05.008

7. Bazan NG, Calandria JM, Gordon WC (2013) Docosahexaenoic acid and its derivative neuroprotectin D1 display neuroprotective properties in the retina, brain and central nervous system. Nestle Nutr Inst Workshop Ser 77:121-131. doi:10.1159/000351395

8. Walsh DM, Selkoe DJ (2004) Deciphering the molecular basis of memory failure in Alzheimer's disease. Neuron 44(1):181-193. doi:10.1016/j.neuron.2004.09.010

9. Sambamurti K, Greig NH, Lahiri DK (2002) Advances in the cellular and molecular biology of the beta-amyloid protein in Alzheimer's disease. Neuromolecul Med 1(1):1-31. doi:10.1385/ nmm:1:1:1

10. Freeman LC, Ting JP (2015) The pathogenic role of the inflammasome in neurodegenerative diseases. J Neurochem. doi:10.1111/jnc. 13217

11. Nishikimi M, Fukuyama R, Minoshima S, Shimizu N, Yagi K (1994) Cloning and chromosomal mapping of the human nonfunctional gene for L-gulono-gamma-lactone oxidase, the enzyme for L-ascorbic acid biosynthesis missing in man. J Biol Chem 269(18):13685-13688

12. Visioli F, Reilly MM, Rimoldi M, Solari A, Pareyson D (2013) Vitamin C and Charcot-Marie-Tooth 1A: pharmacokinetic considerations. PharmaNutrition 1(1):10-12. doi:10.1016/j.phanu.2012. 10.001

13. Frei B, England L, Ames BN (1989) Ascorbate is an outstanding antioxidant in human blood plasma. Proc Natl Acad Sci U S A 86(16):6377-6381

14. Combs J, Gerald F (2012) The vitamins, 4th edn. Elsevier Science, Burlington

15. Murakami K, Murata N, Ozawa Y, Kinoshita N, Irie K, Shirasawa T, Shimizu T (2011) Vitamin C restores behavioral deficits and amyloid-beta oligomerization without affecting plaque formation in a mouse model of Alzheimer's disease. J Alzheimers Dis 26(1): 7-18. doi:10.3233/jad-2011-101971 
16. Harrison FE, Hosseini AH, Dawes SM, Weaver S, May JM (2009) Ascorbic acid attenuates scopolamine-induced spatial learning deficits in the water maze. Behav Brain Res 205(2):550-558. doi:10.1016/j.bbr.2009.08.017

17. Kook SY, Lee KM, Kim Y, Cha MY, Kang S, Baik SH, Lee H, Park R, Mook-Jung I (2014) High-dose of vitamin C supplementation reduces amyloid plaque burden and ameliorates pathological changes in the brain of 5XFAD mice. Cell Death Dis 5, e1083. doi:10.1038/cddis.2014.26

18. Rinaldi P, Polidori MC, Metastasio A, Mariani E, Mattioli P, Cherubini A, Catani M, Cecchetti R, Senin U, Mecocci P (2003) Plasma antioxidants are similarly depleted in mild cognitive impairment and in Alzheimer's disease. Neurobiol Aging 24(7):915919

19. Schmidt R, Hayn M, Reinhart B, Roob G, Schmidt H, Schumacher M, Watzinger N, Launer LJ (1998) Plasma antioxidants and cognitive performance in middle-aged and older adults: results of the Austrian Stroke Prevention Study. J Am Geriatr Soc 46(11):1407-1410

20. Harrison FE (2012) A critical review of vitamin C for the prevention of age-related cognitive decline and Alzheimer's disease. J Alzheimers Dis 29(4):711-726. doi:10.3233/jad-2012-111853

21. Bowman GL, Dodge H, Frei B, Calabrese C, Oken BS, Kaye JA, Quinn JF (2009) Ascorbic acid and rates of cognitive decline in Alzheimer's disease. J Alzheimers Dis 16(1):93-98. doi:10.3233/ jad-2009-0923

22. Emir UE, Raatz S, McPherson S, Hodges JS, Torkelson C, Tawfik P, White T, Terpstra M (2011) Noninvasive quantification of ascorbate and glutathione concentration in the elderly human brain. NMR Biomed 24(7):888-894. doi:10.1002/nbm.1646

23. Timpson NJ, Forouhi NG, Brion MJ, Harbord RM, Cook DG, Johnson P, McConnachie A, Morris RW, Rodriguez S, Luan J, Ebrahim S, Padmanabhan S, Watt G, Bruckdorfer KR, Wareham NJ, Whincup PH, Chanock S, Sattar N, Lawlor DA, Davey Smith G (2010) Genetic variation at the SLC23A1 locus is associated with circulating concentrations of $\mathrm{L}$-ascorbic acid (vitamin $\mathrm{C}$ ): evidence from 5 independent studies with $>15,000$ participants. Am J Clin Nutr 92(2):375-382. doi:10.3945/ajen.2010.29438

24. Michels AJ, Hagen TM, Frei B (2013) Human genetic variation influences vitamin $\mathrm{C}$ homeostasis by altering vitamin $\mathrm{C}$ transport and antioxidant enzyme function. Annu Rev Nutr 33:45-70. doi: 10.1146/annurev-nutr-071812-161246

25. Morris MC, Beckett LA, Scherr PA, Hebert LE, Bennett DA, Field TS, Evans DA (1998) Vitamin E and vitamin C supplement use and risk of incident Alzheimer disease. Alzheimer Dis Assoc Disord 12(3):121-126

26. Engelhart MJ, Geerlings MI, Ruitenberg A, van Swieten JC, Hofman A, Witteman JC, Breteler MM (2002) Dietary intake of antioxidants and risk of Alzheimer disease. JAMA 287(24):32233229

27. Luchsinger JA, Mayeux R (2004) Dietary factors and Alzheimer's disease. Lancet Neurol 3((10):579-587. doi:10.1016/s14744422(04)00878-6

28. Gu Y, Schupf N, Cosentino SA, Luchsinger JA, Scarmeas N (2012) Nutrient intake and plasma beta-amyloid. Neurology 78(23):1832-1840. doi:10.1212/WNL.0b013e318258f7c2

29. Kozyraki R, Cases O (2013) Vitamin B12 absorption: mammalian physiology and acquired and inherited disorders. Biochimie 95(5): 1002-1007. doi:10.1016/j.biochi.2012.11.004

30. Krautler B (2005) Vitamin B12: chemistry and biochemistry. Biochem Soc Trans 33(Pt 4):806-810. doi:10.1042/bst0330806

31. Fenech M (2010) Folate, DNA damage and the aging brain. Mech Ageing Dev 131(4):236-241. doi:10.1016/j.mad.2010.02.004

32. Herbert V (1988) Vitamin B-12: plant sources, requirements, and assay. Am J Clin Nutr 48(3 Suppl):852-858
33. Aaron S, Kumar S, Vijayan J, Jacob J, Alexander M, Gnanamuthu C (2005) Clinical and laboratory features and response to treatment in patients presenting with vitamin B12 deficiency-related neurological syndromes. Neurol India 53(1):55-58, discussion 59

34. Morris MS (2003) Homocysteine and Alzheimer's disease. Lancet Neurol 2(7):425-428

35. Mattson MP, Shea TB (2003) Folate and homocysteine metabolism in neural plasticity and neurodegenerative disorders. Trends Neurosci 26(3):137-146. doi:10.1016/s0166-2236(03)00032-8

36. Seshadri S, Beiser A, Selhub J, Jacques PF, Rosenberg IH, D'Agostino RB, Wilson PW, Wolf PA (2002) Plasma homocysteine as a risk factor for dementia and Alzheimer's disease. $\mathrm{N}$ Engl J Med 346(7):476-483. doi:10.1056/NEJMoa011613

37. Morris MS (2012) The role of B vitamins in preventing and treating cognitive impairment and decline. Advances Nutr (Bethesda, Md) 3(6):801-812. doi:10.3945/an.112.002535

38. Zhang CE, Wei W, Liu YH, Peng JH, Tian Q, Liu GP, Zhang Y, Wang JZ (2009) Hyperhomocysteinemia increases beta-amyloid by enhancing expression of gamma-secretase and phosphorylation of amyloid precursor protein in rat brain. Am J Pathol 174(4): 1481-1491. doi:10.2353/ajpath.2009.081036

39. Zhuo JM, Pratico D (2010) Acceleration of brain amyloidosis in an Alzheimer's disease mouse model by a folate, vitamin B6 and B12-deficient diet. Exp Gerontol 45(3):195-201. doi:10.1016/j. exger.2009.12.005

40. Haan MN, Miller JW, Aiello AE, Whitmer RA, Jagust WJ, Mungas DM, Allen LH, Green R (2007) Homocysteine, B vitamins, and the incidence of dementia and cognitive impairment: results from the Sacramento Area Latino Study on Aging. Am J Clin Nutr 85(2):511-517

41. Moore E, Mander A, Ames D, Carne R, Sanders K, Watters D (2012) Cognitive impairment and vitamin B12: a review. Int Psychogeriatr 24(4):541-556. doi:10.1017/s1041610211002511

42. van der Zwaluw NL, Dhonukshe-Rutten RA, van Wijngaarden JP, Brouwer-Brolsma EM, van de Rest O, Veld PH I 't, Enneman AW, van Dijk SC, Ham AC, Swart KM, van der Velde N, van Schoor NM, van der Cammen TJ, Uitterlinden AG, Lips P, Kessels RP, de Groot LC (2014) Results of 2-year vitamin B treatment on cognitive performance: secondary data from an RCT. Neurology 83(23):2158-2166. doi:10.1212/wnl.0000000000001050

43. Dangour AD, Whitehouse PJ, Rafferty K, Mitchell SA, Smith L, Hawkesworth S, Vellas B (2010) B-vitamins and fatty acids in the prevention and treatment of Alzheimer's disease and dementia: a systematic review. J Alzheimers Dis 22(1):205-224. doi:10.3233/ jad-2010-090940

44. Gilgun-Sherki Y, Melamed E, Offen D (2001) Oxidative stress induced-neurodegenerative diseases: the need for antioxidants that penetrate the blood brain barrier. Neuropharmacology 40(8):959975

45. Krezel W, Kastner P, Chambon P (1999) Differential expression of retinoid receptors in the adult mouse central nervous system. Neuroscience 89(4):1291-1300

46. Goodman AB, Pardee AB (2003) Evidence for defective retinoid transport and function in late onset Alzheimer's disease. Proc Natl Acad Sci U S A 100(5):2901-2905. doi:10.1073/pnas. 0437937100

47. Goncalves MB, Clarke E, Hobbs C, Malmqvist T, Deacon R, Jack J, Corcoran JP (2013) Amyloid beta inhibits retinoic acid synthesis exacerbating Alzheimer disease pathology which can be attenuated by an retinoic acid receptor alpha agonist. Eur J Neurosci 37(7):1182-1192. doi:10.1111/ejn.12142

48. Ono K, Yamada M (2012) Vitamin A and Alzheimer's disease. Geriatr Gerontol Int 12(2):180-188. doi:10.1111/j.1447-0594. 2011.00786.x

49. Corcoran JP, So PL, Maden M (2004) Disruption of the retinoid signalling pathway causes a deposition of amyloid beta in the adult 
rat brain. Eur J Neurosci 20(4):896-902. doi:10.1111/j.14609568.2004.03563.x

50. Chiang MY, Misner D, Kempermann G, Schikorski T, Giguere V, Sucov HM, Gage FH, Stevens CF, Evans RM (1998) An essential role for retinoid receptors RARbeta and RXRgamma in long-term potentiation and depression. Neuron 21(6):1353-1361

51. Ding Y, Qiao A, Wang Z, Goodwin JS, Lee ES, Block ML, Allsbrook M, McDonald MP, Fan GH (2008) Retinoic acid attenuates beta-amyloid deposition and rescues memory deficits in an Alzheimer's disease transgenic mouse model. J Neurosci 28(45): 11622-11634. doi:10.1523/jneurosci.3153-08.2008

52. Misner DL, Jacobs S, Shimizu Y, de Urquiza AM, Solomin L, Perlmann T, De Luca LM, Stevens CF, Evans RM (2001) Vitamin A deprivation results in reversible loss of hippocampal long-term synaptic plasticity. Proc Natl Acad Sci U S A 98(20): 11714-11719. doi:10.1073/pnas. 191369798

53. Lopes da Silva S, Vellas B, Elemans S, Luchsinger J, Kamphuis P, Yaffe K, Sijben J, Groenendijk M, Stijnen T (2014) Plasma nutrient status of patients with Alzheimer's disease: systematic review and meta-analysis. Alzheimers Dement 10(4):485-502. doi:10. 1016/j.jalz.2013.05.1771

54. Zhang H, Gong B, Liu S, Fa M, Ninan I, Staniszewski A, Arancio O (2005) Synaptic fatigue is more pronounced in the APP/PS1 transgenic mouse model of Alzheimer's disease. Curr Alzheimer Res 2(2): 137-140

55. Jarvis CI, Goncalves MB, Clarke E, Dogruel M, Kalindjian SB, Thomas SA, Maden M, Corcoran JP (2010) Retinoic acid receptor-alpha signalling antagonizes both intracellular and extracellular amyloid-beta production and prevents neuronal cell death caused by amyloid-beta. Eur J Neurosci 32(8):1246-1255. doi:10. 1111/j.1460-9568.2010.07426.x

56. Holick MF (2007) Vitamin D deficiency. N Engl J Med 357(3): 266-281. doi:10.1056/NEJMra070553

57. Eyles DW, Smith S, Kinobe R, Hewison M, McGrath JJ (2005) Distribution of the vitamin $\mathrm{D}$ receptor and 1 alpha-hydroxylase in human brain. J Chem Neuroanat 29(1):21-30. doi:10.1016/j. jchemneu.2004.08.006

58. MacLaughlin J, Holick MF (1985) Aging decreases the capacity of human skin to produce vitamin D3. J Clin Invest 76(4):15361538. doi:10.1172/jci112134

59. Wakimoto P, Block G (2001) Dietary intake, dietary patterns, and changes with age: an epidemiological perspective. J Gerontol A Biol Sci Med Sci 56(Spec No 2):65-80

60. Holick MF, Matsuoka LY, Wortsman J (1989) Age, vitamin D, and solar ultraviolet. Lancet 2(8671):1104-1105

61. Kalueff AV, Tuohimaa P (2007) Neurosteroid hormone vitamin D and its utility in clinical nutrition. Curr Opin Clin Nutr Metab Care 10(1):12-19. doi:10.1097/MCO.0b013e328010ca18

62. Littlejohns TJ, Henley WE, Lang IA, Annweiler C, Beauchet O, Chaves PH, Fried L, Kestenbaum BR, Kuller LH, Langa KM, Lopez OL, Kos K, Soni M, Llewellyn DJ (2014) Vitamin D and the risk of dementia and Alzheimer disease. Neurology 83(10): 920-928. doi:10.1212/wnl.0000000000000755

63. Mizwicki MT, Menegaz D, Zhang J, Barrientos-Duran A, Tse S, Cashman JR, Griffin PR, Fiala M (2012) Genomic and nongenomic signaling induced by 1alpha,25(OH)2-vitamin D3 promotes the recovery of amyloid-beta phagocytosis by Alzheimer's disease macrophages. J Alzheimers Dis 29(1):5162. doi:10.3233/jad-2012-110560

64. Durk MR, Han K, Chow EC, Ahrens R, Henderson JT, Fraser PE, Pang KS (2014) 1alpha,25-Dihydroxyvitamin D3 reduces cerebral amyloid-beta accumulation and improves cognition in mouse models of Alzheimer's disease. J Neurosci 34(21):7091-7101. doi:10.1523/jneurosci.2711-13.2014

65. Cardoso BR, Cominetti C, Cozzolino SM (2013) Importance and management of micronutrient deficiencies in patients with
Alzheimer's disease. Clin Interv Aging 8:531-542. doi:10.2147/ cia.s27983

66. Evans HM, Bishop KS (1922) On the existence of a hitherto unrecognized dietary factor essential for reproduction. Science 56(1458):650-651. doi:10.1126/science.56.1458.650

67. Sheppard AJ, Pennington JAT, Weihrauch JL (1993) Analysis and distribution of vitamin $\mathrm{E}$ in vegetable oils and foods. In: Packer L, Fuchs J (eds) Vitamin E in health and disease. Marcel Dekker Inc., New York

68. Ahsan H, Ahad A, Iqbal J, Siddiqui WA (2014) Pharmacological potential of tocotrienols: a review. Nutr Metab (Lond) 11(1):52. doi:10.1186/1743-7075-11-52

69. Iqubal MA, Khan M, Kumar P, Kumar A, Ajai K (2014) Role of vitamin e in prevention of oral cancer: a review. J Clin Diagn Res 8(10):ZE05-ZE07. doi:10.7860/jcdr/2014/9166.4958

70. Kirac D, Negis Y, Ozer NK (2013) Vitamin E attenuates homocysteine and cholesterol induced damage in rat aorta. Cardiovasc Pathol 22(6):465-472. doi:10.1016/j.carpath.2013.03.007

71. Joshi YB, Pratico D (2012) Vitamin E in aging, dementia, and Alzheimer's disease. Biofactors 38(2):90-97. doi:10.1002/biof. 195

72. Zingg JM, Han SN, Pang E, Meydani M, Meydani SN, Azzi A (2013) In vivo regulation of gene transcription by alpha- and gamma-tocopherol in murine T lymphocytes. Arch Biochem Biophys 538(2):111-119. doi:10.1016/j.abb.2013.08.010

73. Brigelius-Flohe R (2009) Vitamin E: the shrew waiting to be tamed. Free Radic Biol Med 46(5):543-554. doi:10.1016/j. freeradbiomed.2008.12.007

74. Jiang Q (2014) Natural forms of vitamin E: metabolism, antioxidant, and anti-inflammatory activities and their role in disease prevention and therapy. Free Radic Biol Med 72:76-90. doi:10. 1016/j.freeradbiomed.2014.03.035

75. Giraldo E, Lloret A, Fuchsberger T, Vina J (2014) Abeta and tau toxicities in Alzheimer's are linked via oxidative stress-induced p38 activation: protective role of vitamin E. Redox Biol 2:873877. doi:10.1016/j.redox.2014.03.002

76. Yatin SM, Varadarajan S, Butterfield DA (2000) Vitamin E prevents alzheimer's amyloid beta-peptide (1-42)-induced neuronal protein oxidation and reactive oxygen species production. $\mathrm{J}$ Alzheimers Dis 2(2):123-131

77. Shea TB, Ortiz D, Nicolosi RJ, Kumar R, Watterson AC (2005) Nanosphere-mediated delivery of vitamin E increases its efficacy against oxidative stress resulting from exposure to amyloid beta. $\mathrm{J}$ Alzheimers Dis 7(4):297-301

78. Kaneai N, Arai M, Takatsu H, Fukui K, Urano S (2012) Vitamin E inhibits oxidative stress-induced denaturation of nerve terminal proteins involved in neurotransmission. J Alzheimers Dis 28(1): 183-189. doi:10.3233/jad-2011-111133

79. Ahmed HH (2012) Modulatory effects of vitamin E, acetyl-Lcarnitine and alpha-lipoic acid on new potential biomarkers for Alzheimer's disease in rat model. Exp Toxicol Pathol 64(6):549 556. doi:10.1016/j.etp.2010.11.012

80. Sung S, Yao Y, Uryu K, Yang H, Lee VM, Trojanowski JQ, Pratico D (2004) Early vitamin E supplementation in young but not aged mice reduces Abeta levels and amyloid deposition in a transgenic model of Alzheimer's disease. FASEB J 18(2):323325. doi:10.1096/fj.03-0961fje

81. Huebbe P, Schaffer S, Jofre-Monseny L, Boesch-Saadatmandi C, Minihane AM, Muller WE, Eckert GP, Rimbach G (2007) Apolipoprotein E genotype and alpha-tocopherol modulate amyloid precursor protein metabolism and cell cycle regulation. Mol Nutr Food Res 51(12):1510-1517. doi:10.1002/mnfr.200700194

82. Takatsu H, Owada K, Abe K, Nakano M, Urano S (2009) Effect of vitamin $\mathrm{E}$ on learning and memory deficit in aged rats. J Nutr Sci Vitaminol (Tokyo) 55(5):389-393 
83. Mangialasche F, Xu W, Kivipelto M, Costanzi E, Ercolani S, Pigliautile M, Cecchetti R, Baglioni M, Simmons A, Soininen H, Tsolaki M, Kloszewska I, Vellas B, Lovestone S, Mecocci P (2012) Tocopherols and tocotrienols plasma levels are associated with cognitive impairment. Neurobiol Aging 33(10):2282-2290. doi:10.1016/j.neurobiolaging.2011.11.019

84. Visioli F (2001) Effects of vitamin $\mathrm{E}$ on the endothelium: equivocal? Alpha-tocopherol and endothelial dysfunction. Cardiovasc Res 51(2):198-201

85. Farina N, Isaac MG, Clark AR, Rusted J, Tabet N (2012) Vitamin E for Alzheimer's dementia and mild cognitive impairment. Cochrane Database Syst Rev 11, CD002854. doi:10.1002/ 14651858.CD002854.pub3

86. Petersen RC, Thomas RG, Grundman M, Bennett D, Doody R, Ferris S, Galasko D, Jin S, Kaye J, Levey A, Pfeiffer E, Sano M, van Dyck CH, Thal LJ (2005) Vitamin E and donepezil for the treatment of mild cognitive impairment. N Engl J Med 352(23): 2379-2388. doi:10.1056/NEJMoa050151

87. Morris MC, Evans DA, Tangney CC, Bienias JL, Wilson RS, Aggarwal NT, Scherr PA (2005) Relation of the tocopherol forms to incident Alzheimer disease and to cognitive change. Am J Clin Nutr 81(2):508-514

88. Walther B, Karl JP, Booth SL, Boyaval P (2013) Menaquinones, bacteria, and the food supply: the relevance of dairy and fermented food products to vitamin $\mathrm{K}$ requirements. Advances Nutr (Bethesda, Md) 4(4):463-473. doi:10.3945/an.113.003855

89. Schurgers LJ, Vermeer C (2000) Determination of phylloquinone and menaquinones in food. Effect of food matrix on circulating vitamin K concentrations. Haemostasis 30((6):298-307

90. Vermeer C, Jie KS, Knapen MH (1995) Role of vitamin K in bone metabolism. Annu Rev Nutr 15:1-22. doi:10.1146/annurev.nu.15. 070195.000245

91. Allison AC (2001) The possible role of vitamin K deficiency in the pathogenesis of Alzheimer's disease and in augmenting brain damage associated with cardiovascular disease. Med Hypotheses 57(2):151-155. doi:10.1054/mehy.2001.1307

92. Theuwissen E, Smit E, Vermeer C (2012) The role of vitamin K in soft-tissue calcification. Advances Nutr (Bethesda, Md) 3(2):166173. doi:10.3945/an.111.001628

93. Presse N, Shatenstein B, Kergoat MJ, Ferland G (2008) Low vitamin $\mathrm{K}$ intakes in community-dwelling elders at an early stage of Alzheimer's disease. J Am Diet Assoc 108(12):2095-2099. doi: 10.1016/j.jada.2008.09.013

94. Sato Y, Honda Y, Hayashida N, Iwamoto J, Kanoko T, Satoh K (2005) Vitamin K deficiency and osteopenia in elderly women with Alzheimer's disease. Arch Phys Med Rehabil 86(3):576581. doi:10.1016/j.apmr.2004.10.005

95. Huy PD, Yu YC, Ngo ST, Thao TV, Chen CP, Li MS, Chen YC (2013) In silico and in vitro characterization of anti-amyloidogenic activity of vitamin $\mathrm{K} 3$ analogues for Alzheimer's disease. Biochim Biophys Acta 1830(4):2960-2969. doi:10.1016/j.bbagen.2012. 12.026

96. Iwamoto J, Sato Y, Tanaka K, Takeda T, Matsumoto H (2009) Prevention of hip fractures by exposure to sunlight and pharmacotherapy in patients with Alzheimer's disease. Aging Clin Exp Res 21(4-5):277-281

97. Schaffer S, Asseburg H, Kuntz S, Muller WE, Eckert GP (2012) Effects of polyphenols on brain ageing and Alzheimer's disease: focus on mitochondria. Mol Neurobiol 46(1):161-178. doi:10. 1007/s12035-012-8282-9

98. Vepsalainen S, Koivisto H, Pekkarinen E, Makinen P, Dobson G, McDougall GJ, Stewart D, Haapasalo A, Karjalainen RO, Tanila H, Hiltunen M (2013) Anthocyanin-enriched bilberry and blackcurrant extracts modulate amyloid precursor protein processing and alleviate behavioral abnormalities in the APP/PS1 mouse model of Alzheimer's disease. J Nutr Biochem 24(1):360-370. doi:10.1016/j.jnutbio.2012.07.006

99. Rubio-Perez JM, Morillas-Ruiz JM (2013) Serum cytokine profile in Alzheimer's disease patients after ingestion of an antioxidant beverage. CNS Neurol Disord Drug Targets 12(8):1233-1241

100. Bastianetto S, Yao ZX, Papadopoulos V, Quirion R (2006) Neuroprotective effects of green and black teas and their catechin gallate esters against beta-amyloid-induced toxicity. Eur J Neurosci 23(1):55-64. doi:10.1111/j.1460-9568.2005.04532.x

101. Rezai-Zadeh K, Arendash GW, Hou H, Fernandez F, Jensen M, Runfeldt M, Shytle RD, Tan J (2008) Green tea epigallocatechin-3gallate (EGCG) reduces beta-amyloid mediated cognitive impairment and modulates tau pathology in Alzheimer transgenic mice. Brain Res 1214:177-187. doi:10.1016/j.brainres.2008.02.107

102. Poli A, Marangoni F, Avogaro A, Barba G, Bellentani S, Bucci M, Cambieri R, Catapano AL, Costanzo S, Cricelli C, de Gaetano G, Di Castelnuovo A, Faggiano P, Fattirolli F, Fontana L, Forlani G, Frattini S, Giacco R, La Vecchia C, Lazzaretto L, Loffredo L, Lucchin L, Marelli G, Marrocco W, Minisola S, Musicco M, Novo S, Nozzoli C, Pelucchi C, Perri L, Pieralli F, Rizzoni D, Sterzi R, Vettor R, Violi F, Visioli F (2013) Moderate alcohol use and health: a consensus document. Nutr Metab Cardiovasc Dis 23(6):487-504. doi:10.1016/j.numecd.2013.02.007

103. Bate C, Williams A (2011) Ethanol protects cultured neurons against amyloid-beta and alpha-synuclein-induced synapse damage. Neuropharmacology 61(8):1406-1412. doi:10.1016/j. neuropharm.2011.08.030

104. Marambaud P, Zhao H, Davies P (2005) Resveratrol promotes clearance of Alzheimer's disease amyloid-beta peptides. J Biol Chem 280(45):37377-37382. doi:10.1074/jbc.M508246200

105. Candelario-Jalil E, de Oliveira AC, Graf S, Bhatia HS, Hull M, Munoz E, Fiebich BL (2007) Resveratrol potently reduces prostaglandin E2 production and free radical formation in lipopolysaccharide-activated primary rat microglia. J Neuroinflammation 4:25. doi:10.1186/1742-2094-4-25

106. Visioli F (2014) The resveratrol fiasco. Pharmacol Res 90:87. doi: 10.1016/j.phrs.2014.08.003

107. Tang PC, Ng YF, Ho S, Gyda M, Chan SW (2014) Resveratrol and cardiovascular health - promising therapeutic or hopeless illusion? Pharmacol Res 90:88-115. doi:10.1016/j.phrs.2014.08. 001

108. Ringman JM, Frautschy SA, Cole GM, Masterman DL, Cummings JL (2005) A potential role of the curry spice curcumin in Alzheimer's disease. Curr Alzheimer Res 2(2):131-136

109. Frautschy SA, Hu W, Kim P, Miller SA, Chu T, Harris-White ME, Cole GM (2001) Phenolic anti-inflammatory antioxidant reversal of Abeta-induced cognitive deficits and neuropathology. Neurobiol Aging 22(6):993-1005

110. Whayne TF, Jr. (2015) Coffee: a selected overview of beneficial or harmful effects on the cardiovascular system? Curr Vasc Pharmacol (in press)

111. Oboh G, Agunloye OM, Akinyemi AJ, Ademiluyi AO, Adefegha SA (2013) Comparative study on the inhibitory effect of caffeic and chlorogenic acids on key enzymes linked to Alzheimer's disease and some pro-oxidant induced oxidative stress in rats' brain-in vitro. Neurochem Res 38(2):413-419. doi:10.1007/s11064-0120935-6

112. Kwon SH, Lee HK, Kim JA, Hong SI, Kim HC, Jo TH, Park YI, Lee CK, Kim YB, Lee SY, Jang CG (2010) Neuroprotective effects of chlorogenic acid on scopolamine-induced amnesia via anti-acetylcholinesterase and anti-oxidative activities in mice. Eur J Pharmacol 649(1-3):210-217. doi:10.1016/j.ejphar.2010. 09.001

113. Heitman E, Ingram DK (2014) Cognitive and neuroprotective effects of chlorogenic acid. Nutr Neurosci. doi:10.1179/ $1476830514 \mathrm{y} .0000000146$ 
114. Gelber RP, Petrovitch H, Masaki KH, Ross GW, White LR (2011) Coffee intake in midlife and risk of dementia and its neuropathologic correlates. J Alzheimers Dis 23(4):607-615. doi:10.3233/ jad-2010-101428

115. Visioli F, Bernaert H, Corti R, Ferri C, Heptinstall S, Molinari E, Poli A, Serafini M, Smit HJ, Vinson JA, Violi F, Paoletti R (2009) Chocolate, lifestyle, and health. Crit Rev Food Sci Nutr 49(4): 299-312. doi:10.1080/10408390802066805

116. Cimini A, Gentile R, D'Angelo B, Benedetti E, Cristiano L, Avantaggiati ML, Giordano A, Ferri C, Desideri G (2013) Cocoa powder triggers neuroprotective and preventive effects in a human Alzheimer's disease model by modulating BDNF signaling pathway. J Cell Biochem 114(10):2209-2220. doi:10.1002/ jcb. 24548

117. Bisson JF, Nejdi A, Rozan P, Hidalgo S, Lalonde R, Messaoudi M (2008) Effects of long-term administration of a cocoa polyphenolic extract (Acticoa powder) on cognitive performances in aged rats. Br J Nutr 100(1):94-101. doi:10. $1017 / \mathrm{s} 0007114507886375$

118. Nehlig A (2013) The neuroprotective effects of cocoa flavanol and its influence on cognitive performance. Br J Clin Pharmacol 75(3): 716-727. doi:10.1111/j.1365-2125.2012.04378.x 